\title{
Sinopse do gênero Parexillis Jordan (Coleoptera, Anthribidae, Anthribinae)
}

\author{
José Ricardo Miras Mermudes ${ }^{1,2}$
}

\author{
${ }^{1}$ Museu de Zoologia, Universidade de São Paulo. Caixa Postal 42494, 04218-970 São Paulo-SP, Brasil. Endereço eletrônico: \\ jrmermudes@uol.com.br \\ ${ }^{2}$ Bolsista FAPESP.
}

\begin{abstract}
Synopsis of the genus Parexillis Jordan, 1904 (Coleoptera, Anthribidae, Anthribinae). The genus is redescribed, with description of a new species, Parexillis wappesi sp. nov. (from Bolivia, Santa Cruz), and a key for the nine known species is provided. The species (except $P$. striatus) are illustrated and comments on their geographic distribution are given.
\end{abstract}

Keywords. Neotropical; new species; Parexillis; Platystomini; taxonomy; synopsis.

Resumo. O gênero Parexillis Jordan, 1904 é redescrito, com a descrição de uma nova espécie, Parexillis wappesi sp. nov. (proveniente da Bolívia, Santa Cruz). Chave para as espécies conhecidas é fornecida. Todas as espécies (exceto P. striatus) são ilustradas e comentários sobre as distribuições geográficas são apresentados.

Palavras-Chave. Espécie nova; Neotropical; Parexillis; Platystomini; taxonomia; sinopse.

O gênero Parexillis foi proposto por JoRDAN (1904) para Parexillis lineatus Jordan, 1904 (espécie-tipo) e Parexillis variegatus Jordan, 1904, ambas do Brasil. JoRDAN (1907) descreveu Parexillis striatus proveniente da Nicarágua. FrIESER (1977) descreveu cinco espécies e apresentou chave para as espécies com ocorrência no Brasil.

Atualmente o gênero inclui oito espécies, com uma única espécie registrada para a América Central (Nicarágua, Chontales), e as demais ocorrendo na América do Sul. Destas, sete são assinaladas para o Brasil, com uma espécie, P. lineatus, alcançando a Bolívia (Cochabamba), e P. flavus Frieser, 1977, a Argentina. Neste estudo apresenta-se a redescrição do gênero com base nas espécies conhecidas até o momento e na descrição de uma nova espécie proveniente da Bolívia (Santa Cruz). Uma chave de identificação para as nove espécies é fornecida.

O material estudado pertence ao American Coleoptera Museum, Bulverde, Texas, Estados Unidos (ACMB), Departamento de Zoologia, Universidade Federal do Paraná, Curitiba (DZUP); Museu Nacional, Universidade Federal do Rio de Janeiro, Rio de Janeiro (MNRJ), Museu de Zoologia da Universidade de São Paulo, São Paulo (MZSP) e National Museum of Natural History, Smithsonian Institution, Washington, D.C., Estados Unidos (USMN).

As mensurações seguem MERMUDES \& NAPP (2004), com exceção de LC, DEO, MLO.

\section{Parexillis Jordan, 1904}

Parexillis Jordan 1904: 284; 1907: 379; Bovie, 1906: 310 (cat.); Wolfrum, 1929: 94 (cat.); Blackwelder, 1947: 771 (cat.); Frieser, 1977: 165; Alonso-Zarazaga \& Lyal, 1999: 33 (cat.).

Espécie-tipo: Parexillis lineatus Jordan, 1904, por designação original.

Comprimento: 1,9-6,4 mm. Tegumento geral castanho (exceto
P. flavus, amarelado; élitros com tegumento verde em $P$. wappesi sp. nov.). Revestimento dorsal, ventral e das pernas com pilosidade alongada, decumbente e moderadamente densa.

Cabeça mais larga que longa, parcialmente encoberta pelo protórax; vértice convexo. Olhos látero-dorsais, subconvexos, não proeminentes; margem anterior fortemente chanfrada; granulação moderadamente fina e com omatídios pouco proeminentes. Fronte tão larga quanto longa, muito discretamente mais estreita perto da base do rostro. Rostro vertical, curto, pouco mais largo que longo. Dorso do rostro com dimorfismo sexual, nos machos, fortemente deprimido, a cada lado da base, na frente dos olhos, e no meio no nível dos escrobos; nas fêmeas, ligeiramente convexo na base. Terço apical no dorso ligeiramente deprimido, com chanfro apical raso a profundo. Lados do rostro subparalelos. Escrobos laterais, distância entre escrobo e olho menor que $1 / 5$ do diâmetro do escrobo, subarredondados e pouco profundos; angulosos ou não na margem basal; margem dorsal careniforme. Mento deprimido, com lobos alargados e amplamente arredondados; chanfro mediano profundo e subarredondado; sem sulcos ou carenas. Mandíbulas delgadas e deprimidas, aguçadas no ápice. Palpos maxilares com o artículo apical mais longo que o primeiro e segundo reunidos. Palpos labiais com os artículos apical e basal subiguais e alongados, cerca de 1/3 mais longos que o segundo artículo; este muito engrossado.

Antenas delgadas, com 11 antenômeros e com dimorfismo sexual acentuado. Nos machos, alongadas, ultrapassam o ápice elitral desde o antenômero VI, clava pouco engrossada; nas fêmeas, mais curtas, alcançam o meio dos élitros; clava algo engrossada. Escapo curto, subpiriforme. Antenômeros II-VIII nodosos no ápice; II curto, ligeiramente mais longo que o escapo; clava distinta, formada pelos antenômeros IX-XI; IX, nos machos alongado, cerca de 2 vezes mais longo que $\mathrm{X}$-XI juntos; nas fêmeas, subigual a X-XI juntos.

Protórax variando de transverso até pouco mais longo que 
largo; lados subparalelos na metade basal, discretamente convergentes na metade apical. Declive basal subvertical. Pronoto subconvexo. Carena basal saliente e inteira, ligeiramente sinuosa no meio. Carena lateral curta, alcança o meio do protórax, oblíqua. Carena basal e lateral com unidades brácteas. Prosterno transverso. Processo prosternal curto, menor que $1 / 3$ da cavidade cotilóide anterior. Procoxas oblongas e projetadas. Escutelo reduzido, retangular a quadrangular. Mesosterno transverso, subplano. Processo mesosternal vertical, pouco projetado no ápice, largura subigual à cavidade cotilóide mediana (exceto $P$. variegatus), os lados subparalelos a discretamente convergentes, ápice arredondado. Metasterno pelo menos 2 vezes mais longo que o mesosterno; sulco da margem anterior vestigial.

Élitros pouco alongados, 1,5 vezes mais longos que a largura umeral; fortemente convexos; margem basal amplamente arredondada, careniforme e fortemente saliente; terço basal com gibosidades desde elevadas a quase nulas. Úmeros não projetados. Lados subparalelos. Ápice arredondado com declive acentuado.

Pernas com comprimentos subiguais. Fêmures subclavados, com pedúnculo curto. Tíbias engrossadas para o ápice, com comprimentos subiguais aos dos fêmures. Tarsômeros I cerca de $1 / 3$ mais longo que o II. Unhas apendiculadas, 1/3 mais longas que o processo interno.

Abdômen. Ventritos estreitos, I-III e o V, no disco, subiguais no comprimento; IV ligeiramente mais curto. Processo intercoxal do ventrito I com sulco próximo da margem. Pigídio pouco mais largo que longo, vertical e subconvexo; margem apical subarredondada.

Distribuição. Nicarágua, Brasil, Bolívia e Argentina.

Discussão. JoRDAN (1906: 299) não concordou com os agrupamentos supragenéricos propostos por LACORDAIRE (1866), argumentando que os grupos não seriam sustentáveis. JoRDAN (1904), quando propôs o gênero Parexillis e depois na diagnose fornecida na Biologia Centrali-Americana (JoRDAN 1907: 379), considerou o gênero relacionado com Exillis Pascoe, 1860, da região Oriental, hoje com distribuição assinalada também para a Polinésia e Austrália (ZimMerman 1994: 122); distinguiu Parexillis de Exillis por apresentar rostro nunca carenado ou sulcado no dorso e pela carena basal do protórax. Em Exillis, o rostro é carenado no dorso e a carena do protórax é antebasal. Alonso-ZarAZAGA \& Lyal (1999) alocaram os dois gêneros na tribo Platystomini Pierce, 1916. No entanto, Parexillis e Exillis são distintos de Platystomos Schneider, 1791 (da região Paleártica, Indonésia, Filipinas e Nova Guiné) principalmente pelos olhos chanfrados e corpo convexo. Estudos mais abrangentes poderão confirmar o posicionamento de Parexillis em Platystomini.

As espécies que compõem Parexillis são muito uniformes morfologicamente. FrIESER (1977) argumentou que as diferenças entre as espécies estavam relacionadas à coloração e principalmente na forma do escrobo e no comprimento do antenômero II. Com a análise do material-tipo das espécies de
Frieser e de outros exemplares das instituições citadas acima, foi possível verificar a variação dos dois últimos caracteres para a maioria das espécies. Desta forma, uma nova chave, agora com nove espécies, é apresentada com base em caracteres do revestimento, pontuação do corpo e outros caracteres morfológicos, principalmente do rostro e élitros.

\section{Chave para as espécies de Parexillis}

1. Élitros com faixas longitudinais inteiras, da base ao ápice

Élitros sem faixas longitudinais inteiras, apenas com manchas irregulares ................................................... 4

2(1). Pronoto com três faixas longitudinais. NICARÁGUA (Chontales) ............................... P. striatus Jordan, 1907

Pronoto com uma única linha estreita e mediana, pouco definida . .3

3(2). Élitros com uma faixa longitudinal, ao longo da interestria sutural; margem apical do rostro sinuosa. (Fig. 1). BRASIL (Amazonas, Pará) ....... P. divisus Frieser, 1977

Élitros com faixas longitudinais em interestrias alternadas; margem apical do rostro sub-retilínea. (Fig. 2). BOLÍVIA (Cochabamba), BRASIL (Minas Gerais e Santa Catarina) P. lineatus Jordan, 1904

4(1). Chanfro apical do rostro profundo 5

Chanfro apical do rostro raso 7

5(4). Revestimento dorsal, ventral e das pernas com pilosidade amarelada esparsa. Lados da fronte, vértice e pronoto com faixa de pilosidade esbranquiçada, densa que alcança os lados dos úmeros. Élitros com gibosidades basais manifestas, com a interestria 3 saliente na gibosidade. (Fig. 3). BOLÍVIA (Santa Cruz) ...

P. wappesi sp. nov.

Revestimento dorsal, ventral e das pernas com pilosidade acinzentada a amarelada e densa. Cabeça e pronoto sem faixas laterais. Élitros com gibosidades basais quase nulas

6

6(5). Pontuação no dorso do rostro, da cabeça e do pronoto grossa, sem estrias longitudinais. Pronoto subplano. Prosterno opaco, sem grânulos. (Fig. 4). BRASIL (Pará) P. planulus Frieser, 1977

Pontuação no dorso do rostro, da cabeça e do pronoto confluente, formando estrias longitudinais. Pronoto com discreta elevação no disco. Prosterno opaco com grânulos. (Fig. 5). BRASIL (Espírito Santo) ..............

P. corpulentus Frieser, 1977

7(4). Tegumento amarelado a castanho-amarelado. Revestimento dorsal com manchas de pilosidade de cor castanha nitidamente contrastantes com a pilosidade amarelada; nos élitros com duas manchas 
transversais, uma pós-mediana e outra ante-apical. Pontuação no dorso do rostro, da cabeça e do pronoto com microestrias longitudinais. (Fig. 6). BRASIL (São Paulo, Santa Catarina), ARGENTINA (Tucumán) ........ P. flavus Frieser, 1977

Tegumento castanho-claro a escuro. Revestimento dorsal com manchas de pilosidade de cor castanha pouco contrastantes com a pilosidade amarelada; nos élitros formam na região pós-mediana e ante-apical, manchas isoladas e irregulares. Pontuação no dorso do rostro, da cabeça e do pronoto sem microestrias longitudinais

.... 8

8(7). Pontuação do pronoto com pontos grossos coalescentes, interstícios microesculturados e elevados, com aspecto de rugas irregulares curtas e transversas. Prosterno com pontos grossos e microesculturado. Processo mesosternal ligeiramente mais largo que metade da cavidade cotilóide mediana. Élitros com gibosidades basais manifestas. (Fig. 7). BRASIL (Rio de Janeiro ao Rio Grande do Sul) .................... P. remotus Frieser, 1977

Pontuação do pronoto com pontos subcontíguos, com aspecto foveolado. Prosterno com grânulos elevados e conspícuos. Processo mesosternal estreito, a largura menor que metade da cavidade cotilóide mediana. Élitros com gibosidades basais nulas. (Fig. 8). BRASIL (Rio de Janeiro a Santa Catarina) P. variegatus Jordan, 1904

\section{Parexillis striatus Jordan, 1907}

Parexillis striatus Jordan, 1907: 380; Wolfrum, 1929: 94 (cat.); Blackwelder, 1947: 771 (cat.).

Espécie conhecida apenas do holótipo macho, de Chontales, Nicarágua, não examinado e depositado no The Natural History Museum, Londres. Jordan (1907) descreveu e ilustrou $P$. striatus. A descrição original e a figura 26, Tab. XIV, permitiram a inclusão desta espécie na presente chave de identificação.

JORDAN (1907) considerou a espécie proximamente relacionada a P. lineatus Jordan, 1904, do Brasil. Os caracteres diagnósticos desta espécie são a presença de três faixas contínuas do pronoto à cabeça, e os élitros com faixas claras dispostas em interestrias alternadas, sendo que as faixas das interestrias 3 e 9 são contínuas da base ao ápice dos élitros.

\section{Parexillis divisus Frieser, 1977} (Fig. 1)

Parexillis divisus Frieser, 1977: 165.

FrIESER (1977) citou que esta espécie apresenta o dorso do corpo uniformemente castanho, com estreita faixa mediana desde o pronoto até o ápice dos élitros, ao longo da interestria sutural. A pubescência é de cor castanha, intercalada com um pouco de pubescência branca. O exame do holótipo macho e de 31 parátipos depositados no MZSP e de uma nova série da mesma localidade, permitiu verificar que o tegumento desta espécie é castanho-escuro com densa pilosidade esbranquiçada, quase indistinta da faixa longitudinal que apresenta pilosidade mais densa e branca. O material-tipo do MZSP é citado novamente nesta contribuição, fornecendo-se o sexo dos exemplares examinados.

Material-tipo examinado. BRASIL. Pará: Jacareacanga, Holótipo macho, I.1969, F. R. Barbosa col. (MZSP). Parátipos: com os mesmos dados do holótipo, 5 machos e 14 fêmeas; com mesmo local e coletor, 1 macho e 4 fêmeas, XI.1969, 2 fêmeas, I.1970, 1 macho e 2 fêmeas, II.1970; mesmo local, 1 macho, III.1969, sem coletor, ex-coleção Fragoso; 1 fêmea do Amazonas: Maturacá (alto Rio Cabuaburi), 1720.I.1963, J. Bechyné col. (MZSP).

Material examinado. BRASIL. Pará: Jacareacanga, 1 macho e 2 fêmeas, XII.1968, Alvarenga col. (MNRJ); 4 machos e 1 fêmea, I.1969, 2 machos e 6 fêmeas IV.1969, F. R. Barbosa col. (MZSP).

\section{Parexillis lineatus Jordan, 1904} (Fig. 2)

Parexillis lineatus Jordan 1904: 284; Bovie, 1906: 310 (cat.); Frieser, 1977: 165; Wolfrum, 1929: 94 (cat.); Blackwelder, 1947: 771 (cat).

Esta espécie apresenta, nos élitros, faixas de pilosidade branca e densa em interestrias alternadas. Distingue-se de $P$. striatus Jordan, 1907 por apresentar todas as faixas contínuas da base ao ápice dos élitros, e o pronoto sem faixas longitudinais. A superfície dorsal do rostro, cabeça e pronoto, rugosa com microestrias longitudinais, diferencia esta espécie de $P$. striatus e de P. divisus. Este tipo de escultura do tegumento só ocorre em $P$. lineatus, $P$. corpulentus e $P$. flavus.

Distribuição. Bolívia (Cochabamba) e Brasil [Santa Catarina, Seara (=Nova Teutônia)] segundo Frieser (1977). A distribuição é ampliada com um novo registro para Minas Gerais, Pedra Azul.

Material examinado. BRASIL. Minas Gerais: Pedra Azul (700m), 2 machos e 2 fêmeas (MNRJ), 1 macho e 1 fêmea, XI.1972, Seabra \& Oliveira col. (MZSP)

\section{Parexillis wappesi sp. nov.} (Fig. 3)

Macho. Tegumento geral castanho; ápice dos antenômeros e toda a clava castanho-escuros; élitros verdes a castanhos; região ventral do corpo com tegumento preto, exceto o último ventrito, castanho; fêmures com tegumento preto, exceto base e ápice. Revestimento (Fig. 3) dorsal, ventral e pernas, com pilosidade amarelada e moderadamente densa. Lados da fronte, do vértice e a cada lado do pronoto, com pilosidade esbranquiçada e densa, formando uma faixa clara que alcança os lados dos úmeros. Pronoto com linha longitudinal clara, subdividida ou não; região central com três faixas longitudinais escuras, formadas por pilosidade castanho-escura, duas mais longas a cada lado do disco, uma mediana e basal mais curta. Élitros com diminuta mancha de pilosidade branca na interestria 3 , após a gibosidade basal, e no meio do declive apical, entre a sutura e interestria 3. Antenas com pilosidade mais fina, esbranquiçada, pouco mais densa na clava. Antenômeros III- 

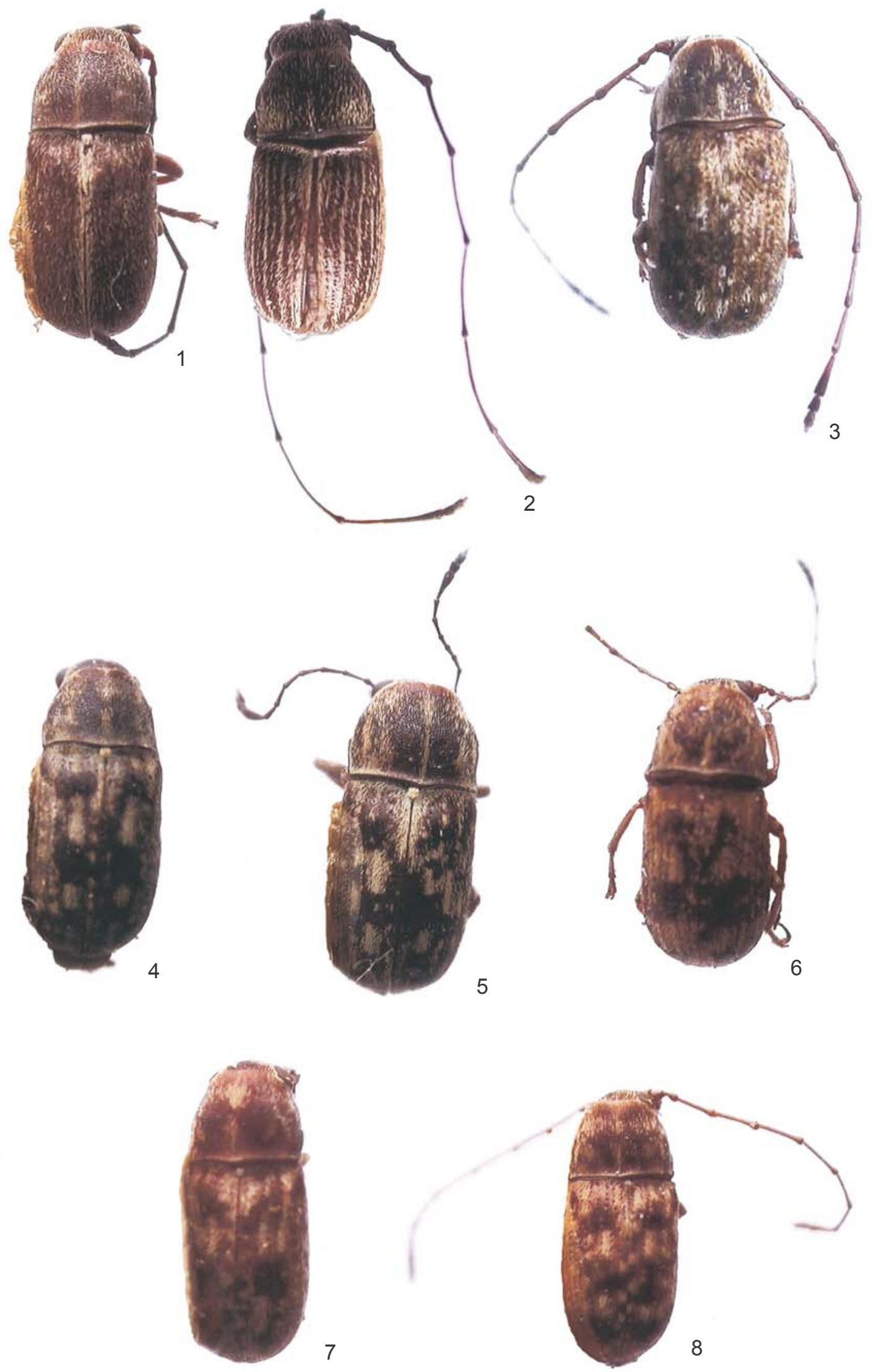

Figs. 1-8. 1, Parexillis divisus Frieser, 1977, holótipo macho; 2, P. lineatus Jordan, 1904; 3, P. wappesi sp. nov., holótipo macho; 4, P. planulus Frieser, 1977, parátipo fêmea; 5, P. corpulentus Frieser, 1977, parátipo fêmea; 6, P. flavus Frieser, 1977, parátipo fêmea; 7, P. remotus Frieser, 1977, parátipo fêmea; 8, P. variegatus Jordan, 1904. 
$\mathrm{V}$, na superfície ventral, com cerdas pouco alongadas, semieretas e esparsas.

Cabeça tão larga quanto o rostro; orla ventral fortemente pontuado-corrugada. Rostro quase 2 vezes mais largo que longo; chanfro apical profundo. Escrobos subarredondados e amplos, muito discretamente anguloso na base, na frente do chanfro ocular. Olhos profundamente chanfrados; chanfro subigual a um terço do diâmetro ocular. Mento com asperosidades e pilosidade amarelada, semidecumbente, esparsas.

Antenas ultrapassam o ápice elitral na metade apical do antenômero VI ou VII. Escapo subigual ao comprimento do antenômero II, este alargado para o ápice; III-IV, subiguais no comprimento, 3 vezes mais longos que o II; V-VIII discretamente decrescentes; IX subigual ao VIII; X mais longo que largo, desde subigual a $1 / 3$ do comprimento do IX; XI subigual ao X, este apendiculado no ápice ( $\mathrm{II}=0,2 ; \mathrm{III}=0,5-07 ; \mathrm{IV}=0,5-0,8 ; \mathrm{V}$ $=0,5-0,9 ; \mathrm{VI}=0,4-0,9 ; \mathrm{VII}=0,4-0,8 ; \mathrm{VIII}=0,4-0,7 ; \mathrm{IX}=0,3-0,7 ; \mathrm{X}$ $=0,2 ; \mathrm{XI}=0,3)$.

Protórax pouco mais largo que longo; com discreta elevação no disco. Carena basal fortemente bissinuosa e elevada; carena lateral curta e oblíqua, alcança o meio do protórax; com ângulo reto entre as carenas. Prosterno fortemente transverso e elevado transversalmente; pontuação grossa e densa. Processo prosternal triangular. Escutelo pouco mais longo que largo. Élitros fortemente convexos; gibosidades basais manifestas, com a interestria 3 saliente na gibosidade.

Abdômen. Ventritos I-V estreitos e subiguais. Pigídio pouco mais largo que longo, vertical e subconvexo; margem apical arredondada.

Dimensões em mm, machos. $\mathrm{CT}=2,8-3,2 ; \mathrm{CR}=0,3-0,4$; $\mathrm{LAR}=0,6-0,7 ; \mathrm{LBR}=0,6-0,7 ; \mathrm{CP}=0,9 ; \mathrm{LP}=1,2-1,4 ; \mathrm{CE}=1,8$ 2,$2 ; \mathrm{LE}=1,2-1,4$.

Fêmea. Desconhecida.

Holótipo macho: BOLÍVIA, Santa Cruz, 4-5 k N Achira, Rd. to Amboro, 12-13.Oct., 2000, Wappes \& Dozier col. (USNM). Parátipos: 2 machos com os mesmos dados do holótipo (ACMB, MZSP.

Discussão. Paraxellis wappesi sp. nov. distingue-se das demais espécies do gênero pelo padrão do tegumento e do revestimento dorsal descritos acima e pelas gibosidades basais manifestas com a interestria 3 saliente. Um parátipo (MZSP) apresenta o tegumento elitral castanho, diferente dos outros dois exemplares com tegumento elitral verde.

O nome desta espécie é dedicada ao colega Joseph Wappes (ACMB), Bulverde, Texas, pelo empréstimo de material e amizade.

\section{Parexillis planulus Frieser, 1977} (Fig. 4)

Parexillis planulus Frieser, 1977: 166.

Pelo padrão do revestimento é quase impossível distinguir esta espécie de $P$. corpulentus, $P$. remotus e $P$. variegatus. Distingue-se das demais pelos caracteres estruturais mencionados na chave, principalmente pelo pronoto quase plano. Espécie conhecida apenas da localidade-tipo, Jacareacanga (Pará).

Material-tipo. Holótipo fêmea, I.1970, e dois parátipos fềmea, I.1969 e XI.1969, examinados. BRASIL. Pará: Jacareacanga, F. R. Barbosa col. (MZSP).

\section{Parexillis corpulentus Frieser, 1977}

(Fig. 5)

Parexillis corpulentus Frieser, 1977: 166

FriESER (1977) comentou que a pubescência cinza, sobre o disco do élitro, forma, muitas vezes, curtas faixas longitudinais. Através do exame de exemplares da localidade-tipo e do materialtipo foi possível verificar que o revestimento nesta espécie varia de cinza a amarelo e que, raramente, apresenta um padrão de faixas curtas nos élitros. A pontuação no dorso do rostro, da cabeça e do pronoto confluente, formando estrias longitudinais; pronoto com discreta elevação no disco; e o prosterno opaco com grânulos, permite distinguir esta espécie de $P$. flavus como das demais espécies com padrão de revestimento semelhante (P. remotus e $P$. variegatus).

Material-tipo. Holótipo fêmea e quatro parátipos fêmeas, examinados. BRASIL. Espirito Santo: Linhares, X.1972, P. C. Elias col. (MZSP).

Material examinado. BRASIL. Espírito Santo: Linhares, 33 machos e 18 fêmeas, XI.1973-II.1975, C. Elias col. (15 machos e 10 fêmeas no MZSP; 18 machos e 8 fêmeas no MNRJ); (Parque Sooretama), 1 macho, XI.1967, F. M. Oliveira col. (DZUP).

\section{Parexillis flavus Frieser, 1977}

(Fig. 6)

Parexillis flavus Frieser, 1977: 167.

FrIESER (1977) citou 45 parátipos fêmeas de Santa Catarina no MZSP. Deste total, foram localizados e estudados apenas 38 , todos de Seara (= Nova Teutônia) [Santa Catarina] mas, ao contrário do que citou Frieser (l. c.), 6 parátipos são machos. Outro parátipo macho como citado por Frieser $(l . c$. $)$ de São Paulo, Ilha dos Búzios.

Os caracteres mencionados na chave distinguem esta espécie das demais com chanfro apical do rostro raso.

Distribuição. Frieser (1977) citou São Paulo (Ilha dos Búzios), Santa Catarina (Seara) e Argentina (Tucumán).

Material examinado. BRASIL. São Paulo: 1 macho, 23.I.1915, s/ col.; São Paulo (Saúde), 1 macho, 4.I.1919; (Jabaquara), 1 macho, 1.XII.1945, Zellibor col. (MNRJ). Santa Catarina: São Bento do Sul (Rio Vermelho), 1 macho, III.1964, Dirings col. (MZSP).

\section{Parexillis remotus Frieser, 1977} (Fig. 7)

Parexillis remotus Frieser, 1977: 166.

FrIESER (1977) propôs $P$. remotus com base em 42 machos e 
34 fêmeas. Depois, sem especificar, afirmou que depositou " 42 " machos e 30 fêmeas provenientes de Santa Catarina (Nova Teutônia) na sua coleção particular e nas seguintes instituições: The Natural History Museum, Londres; Museum Budapest, Zoologische Museum, Berlim, Institut F. Pflanzenschutz, Eberswalde e Museu de Zoologia, São Paulo. Na realidade, tratam-se de 41 parátipos machos, já que os machos do material estudado eram 42 (incluído o holótipo). No MZSP, os parátipos de Santa Catarina não foram localizados.

FRIESER (1977: 167) comentou que examinou a série síntipica de $P$. variegatus Jordan, 1904 e esta incluía exemplares de outras duas espécies que foram propostas por ele, $P$. remotus e $P$. flavus, mas não citou os exemplares da série de Jordan no material-tipo destas espécies. Diante disso, as ocorrências de P. remotus e P. flavus em Goiás (Jataí) e Bahia (Santo Antonio da Barra, atual Condeúba), procedências do material de JORDAN (1904), só poderão ser comprovadas quando o material do The Natural History Museum for examinado.

Parexillis remotus difere de $P$. variegatus pelos caracteres mencionados na chave.

Material-tipo. Parátipos, 2 fêmeas examinadas. BRASIL. São Paulo: Santo André (Vila Bastos), 1 fêmea, 17.II.1962, L. Stowbunenko col. (MZSP). Rio de Janeiro: Rio de Janeiro (Corcovado), 1 fêmea, IX.1967, Alvarenga \& Seabra col. (MZSP).

Material examinado. BRASIL. Rio de Janeiro: Rio de Janeiro (Corcovado), 1 fêmea, X.1968, Alvarenga \& Seabra col. (MNRJ). Paraná: Jussara (H. Florestal, 340 m), 1 macho, 12-15.II.1974, Exp. Depto. Zool. UFPR col. (DZUP). Santa Catarina: Seara (=Nova Teutônia), 1 macho, X.1973, Plaumann col. (DZUP).

\section{Parexillis variegatus Jordan, 1904} (Fig. 8)

Parexillis variegatus Jordan, 1904: 285

JORDAN (1904) propôs esta espécie com base em uma série de exemplares, sem especificar o número exato. O holótipo macho, do Rio de Janeiro (Tijuca), e um parátipo macho, depositado no The Natural History Museum, Londres, foram examinados por FrIESER (1977: 167) que não mencionou a localidade do parátipo. Os outros exemplares de Goiás e Bahia (como discutido em P. remotus, acima) pertencem a duas outras espécies, P. remotus e P. flavus.

FRIESER (1977) comparou o holótipo com duas fêmeas de São Paulo, Ilha da Vitória. Apenas um destes exemplares foi localizado e examinado. Este apresenta data diferente da publicada por FrIESER (1977): 29.III-6.IV.1965.

Esta espécie é muito semelhante à $P$. remotus mas difere pelos caracteres mencionados na chave.

Material examinado. BRASIL. Rio de Janeiro: Rio de Janeiro (Guanabara, Represa Rio Grande), 4 machos, IX.1960 (MNRJ), 1 macho, X.1960 (MZSP), F. M. Oliveira col.

Agradecimentos. À Marcela L. Monné (MZSP) pela leitura crítica do manuscrito e à Sônia Casari (MZSP) pelo empréstimo do equipamento fotográfico. À FAPESP (processos $n^{\circ}$ 03/01863-0 e nº 03/01862-4) pelo suporte financeiro.

\section{REFERÊNCIAS}

Alonso-Zarazaga, M. A. \& C. H. C. Lyal. 1999. A World Catalogue of Families and Genera of Curculionoidea (Insecta: Coleoptera) (Excepting Scolytidae and Platypodidae). Barcelona, Entomopraxis, $315 \mathrm{p}$.

Blackwelder, R. E. 1947. Checklist of the coleopterous insects of Mexico, Central América, the West Indies and South América. Bulletin of the United States National Museum 185(5): 765-925.

Bovie, A. 1906. Catalogue des Anthribides. Annales de la Société Entomologique de Belgique 49: 218-334.

Frieser, R. 1977. The Brazilian species of the genus Parexillis Jordan (Coleoptera, Anthribidae). Revista Brasileira de Entomologia 20(3/4): 165-168.

Jordan, K. 1904. American Anthribidae. Novitates 11(2): 242-309.

JORDAN, K. 1906-1907. Insecta. Coleoptera. Rhynchophora. Anthribidae, p. 299-396. In: D. Sharp, F. Z. S. Blandford \& K. Jordan. 1895-1907. Biologia Centrali-Americana 4 (part. 6). Londres, Britsh Museum (Natural History Museum), vi +396 p. +14 pl.

Lacordaire, T. 1866. Histoire Naturelle des Insectes. Genera des Coléoptères. Vol. 7. Paris, Roret, 620 p.

Mermudes, J. R. M. \& D. S. Napp. 2004. Duas novas espécies de Ptychoderes Schoenherr (Coleoptera, Anthribidae, Anthribinae, Ptychoderini). Revista Brasileira de Entomologia 48(1): 27-30.

Wolfrum, P. 1929. Coleopterorum Catalogus, pars 102, Anthribidae. Berlin, W. Junk, 145 p.

Zimmerman, E. C. 1994. Australian Weevils (Coleoptera: Curculionoidea). Vol. I. Orthoceri. Anthribidae to Attelabidae. The Primitive Weevils. East Melbourne, CSIRO, xxxii +741 p. 